\title{
THE ROLE OF L. METHIONINE, L. CARNITINE, CHOLINE AND/OR SI- LYMARIN IN HEPATOPROTECTION AGAINST PARACETAMOL INTOX- ICATION AND OXIDATIVE STRESS IN BROILERS
}

\author{
Mustafa A. Aziz¹, Abu Elnasr A. Zahra', Zaghloul A. Kheder², Hend M. Fikry²* \\ 1Department of Pharmacology, Faculty of Veterinary Medicine, Kafrelsheikh University, Egypt, \\ ${ }^{2}$ Animal Health Research Institute, Mansoura Provinical Lab, Egypt \\ ${ }^{*}$ Corresponding author, E-mail: hendfikry999@gmail.com
}

\begin{abstract}
Paracetamol (Acetaminophen) was used for long time in poultry as an antipyretic drug and as a growth stimulator. However, high doses of paracetamol cause unpleasant side effects such as hepatorenal toxicity as mirrored by depletion of glutathione reserve, increase lipid peroxidation and increase liver enzymes or even sudden death with lethal doses. Therefore, this study was designated to evaluate the ameliorative effect of L. methionine, L. carnitine, choline and/or silymarin on the hepatotoxic effect induced by high doses of paracetamol. The study was applied on 80 chicks (from 1 till 33 days old) in special cages divided into 8 groups each one contained 10 chicks. The $1^{\text {st }}$ group was used as a control, while the next 2-5 groups were supplemented with L. methionine, L. carnitine, choline and silymarin, respectively with doses as recommended by NRC, the $5^{\text {th }}$ group was supplemented with silymarin $(1 \mathrm{~g} / \mathrm{kg} \mathrm{diet})$, the $6^{\text {th }} \mathrm{group}$ was supplemented with a mixture of the 4 supplements, the $7^{\text {th }}$ group (hepatic intoxicated group) was given paracetamol (650 $\mathrm{mg} / \mathrm{kg}$ diet for 7 days), and the $8^{\text {th }}$ group was administrated paracetamol with a mixture of the 4 supplements. Serum samples were collected to determine levels of lipid profile [triglycerides (TG) and total cholesterol (TC)], liver damage enzymes [alanine transaminase (ALT), aspartate transferase (AST)], lipid peroxidation marker malondialdehyde (MDA), and activity of antioxidant enzymes [glutathione reductase (GR), superoxide dismutase (SOD)]. The obtained results revealed that there was a significant improvement in all measured serum biochemical parameters and final body weight gain in the combined group (4 supplements + paracetamol) as compared to the paracetamol group. These data conclude that supplementation of poultry diets with $L$. methionine, L. carnitine, choline and silymarin can improve the negative effect of paracetamol through increasing the body weight gain and antioxidant activity of glutathione and superoxide dismutase and decreasing malondialdehyde, liver enzymes, cholesterol and triglycerides.
\end{abstract}

Key words: L. methionine; choline; L. carnitine; silymarin; hepatoprotection; broilers

\section{Introduction}

Paracetamol was used for long time as an antipyretic drug and as a growth stimulator. There was unpleasant side effects of paracetamol with 
high doses as hepatorenal damage (1). Toxic effect of paracetamol is caused by its toxic metabolite N-acetyl-P-benzoquinone imine which is normally conjugated with glutathione in liver and converted into mercapturic acid which is not toxic and excreted by kidney. High doses of paracetamol cause toxic metabolite accumulation which leads to depletion of glutathione reserve, increases liver enzymes levels in blood, lipid peroxidation and consequently leads to hepatic necrosis (2).

There are ongoing trends of improving poultry performance and productivity in ways that are different from antibiotics (3). Supplementing poultry diets with different amino acids improve health status of productive animals especially in organic poultry systems (4). Rapid growth, higher feed intake, lower feed conversion ratio and higher final body weight could be recently achieved by many natural supplements to poultry diets (5).

Methionine is an essential sulphur containing amino acid which is important to the health and growth of broilers either when given in natural or synthetic form (6). Poultry performance and body weight are affected by methionine supply but not by the methionine source. While, deficiency of methionine in poultry diets increased the redness value of post mortem tissue (7). High methionine supplemented poultry diet positively affects broiler growth performance and meat quality (8). On the other hand, broiler fed methionine supplemented diet for days then slaughtered and processed showed high meat quality as fresh smell and fresh red color during storage (9).

Choline is an important amino acid in poultry nutrition due to its stimulatory effect on growth. Higher choline concentration in poultry diets results in higher growth rate and average daily feed intake (10). Another study by Saunderson and Mackinlay (11) evaluated the effect of methionine and choline supplementation to poultry diets and found that low methionine level significantly decreased the growth rate and cystathionine beta-synthase enzyme acivity, while high choline level increased significantly choline oxidase enzyme activity.
L. carnitine is the main abdominal fat lowering supplementer in poultry diets beside its growth enhancement effect (12). The same results were obtained by Leibetseder (13) who found that feeding chickens with $500 \mathrm{mg} \mathrm{L}$. carnitine lead to a reduction in the abdominal fat and serum and yolk cholesterol levels and feed conversion ratio but with increased body weight gain and poultry performance. L. carnitine lowers subcutaneous fat deposition through reducing fat metabolism enzymes activity such as glucouse -6- phosphate dehydrogenase, malic dehydrogenase, isocitrate dehydrogenase and lipo protein lipase (14).

It is well known that silymarin has a prominent hepatocyte protective effect in hepatic intoxication caused by ochratoxin A or paracetamol, via its anti-oxidative and anti-apoptotic effect as well as through increasing superoxide dismutase (SOD) and glutathione peroxidase (GPx) activity and decreasing lipid peroxidation product malondialdehyde (15). Moreover, it has a performance enhancement effect as revealed by increasing daily feed intake and final weight gain (16).

This study was planned to investigate the potential ameliorative effect of L. methionine, choline, L. carnitine and silymarin on liver intoxication induced by paracetamol high doses through measuring serum AST, ALT, lipid peroxidation product (malondialdehyde), cholesterol and triglycerides levels, SOD and GPx activity. The effect of these 4 supplements on growth performance was also investigated.

\section{Materials and methods}

The experimental protocol was approved by the Animal Care and Use Committee of Faculty of Veterinary Medicine, Kafrelsheikh University.

A total number of 80 mixed sex Ross 308 broiler chicks at 1 day old age were obtained from a private poultry company at Kafrelsheikh Governorate, Egypt. All the chicks were immunized against both New Castle's disease on $7^{\text {th }}$ and $18^{\text {th }}$ days and Gumboro disease on $14^{\text {th }}$ day. The experimental birds were offered feed and water ad libitum for 33 days. A starter diet was available for the first 21 days then changed 
to a grower diet till the end of the experiment (33 days). Diets were formulated to meet the supplement recommendations for broilers by the National Research Council with some modification according to updated nutrients specification of broiler chickens.

Chicks were divided into 8 equal groups. The $1^{\text {st }}$ group was used as a control, while the next 2-5 groups were supplemented with L. methionine, L. carnitine, choline and silymarin, respectively with doses as recommended by $\mathrm{NRC}$, the $5^{\text {th }}$ group was supplemented with silymarin $(1 \mathrm{~g} / \mathrm{kg}$ diet $)$, the $6^{\text {th }}$ group was supplemented with a mixture of the 4 supplements, the $7^{\text {th }}$ group (hepatic intoxicated group) was given paracetamol $(650 \mathrm{mg} / \mathrm{kg}$ diet for 7 days, orally by gastric tube), and the $8^{\text {th }}$ group was administrated paracetamol with a mixture of the 4 supplements. The doses were given each first 3 days of each week till 33 days age.

Body weight was recorded at the end of every week. Final body weight gain was calculated following this equation: final body weight gain $=$ final weight - start weight .

Blood samples were collected from wing vein. Serum was prepared as previously described (17) and was used to determine SOD, GR, MDA, cholesterol, triglycerides, ALT and AST levels using commercially available kits and as previously described (18-20).

Data were analyzed using One Way ANOVA test with post Hoc Tukey test was used to compare between groups using IBM SPSS software package version 20.0. Quantitative data were described using mean \pm standard error. Significance of the obtained results was judged at $\mathrm{p} \leq 0.05$.

\section{Results and discussion}

\section{Effect of the 4 supplements on final body weight gain}

The present study showed that paracetamol group showed a significant decrease in the final body weight gain as compared to the control group. While L. methionine, L. carnitine, choline and the 4 supplements combined groups showed a significant increase in the final body weight compared to the control group. Moreover, chicken administrated the 4 supplements and paracetamol showed a significant increase in final body weight compared to the paracetamol group without statistical change relative to the control group (Table 1). This means that these 4 supplements had the ability to improve the reduced body weight induced by paracetamol. In consistence with our findings, Jahanian and Khalifeh-Gholi (21) also reported that supplementation of broiler diets with methionine at NRC recommendation levels Ross 308 broiler chicks led to increasing feed conversion ratio and final body weight.

\section{Effect of the 4 supplements on triglycerides} and total cholesterol

The present study reported that paracetamol group showed a significant increase $(\mathrm{p}<0.001)$ in TG and TC levels as compared to the control group (Table 1). L. methionine, choline, L. carnitine and combined groups showed a significant decrease in TG and TC levels, with best effect for combined group, as compared to the control group. Moreover, chicken administrated the 4 supplements and paracetamol showed a significant decrease $(\mathrm{p}<0.002)$ in TG and TC levels as compared to the paracetamol group without statistical change relative to the control group (Table 1). This means that these 4 supplements had the ability to reduce the elevated TG and TC levels triggered by paracetamol. In agreement, Jahanian and Ashnagar (22) reported that chicks fed diet supplemented with choline and L. carnitine had a decreased feed conversion ratio and leg fat content and total plasma lipid level. Similarly, Khajali and Khajali (23) also found a decreasing in total plasma cholesterol and abdominal fat deposition in chicks fed diet supplemented with 200 $\mathrm{mg} / \mathrm{kg}$ of L. carnitine.

\section{Effect of the 4 supplements on ALT and AST}

The paracetamol group showed a significant increase $(\mathrm{p}<0.001)$ in ALT and AST levels as compared to the control group. While chicks fed on diet supplemented with the 4 supplements each alone or in combination, with best effect for combined group, showed a significant decrease level of these two liver enzymes as compared to the control group. Moreover, 
chicken administrated the 4 supplements and paracetamol showed a significant decrease $(\mathrm{p}<0.001)$ in ALT and AST as compared to the paracetamol group without statistical change relative to the control group (Table 2). This indicates that these 4 supplements had the ability to decrease the elevated AST and ALT elevated by paracetamol. In support, Tedesco, et al. (24) also reported a similar anti-hepatotoxic effect for silymarin $(600 \mathrm{mg} / \mathrm{kg})$ as revealed by reduction in AST and ALT level in chicks. Additionally Selvan et al. (25) reported that broiler diets deficient in choline resulted in elevation of liver enzymes and liver histopathology showed many abnormalities and fatty liver.

Table 1: Effect of the 4 supplements on final body weight gain and lipid profile parameter

\begin{tabular}{|l|l|l|l|}
\hline & \multicolumn{1}{|c|}{$\begin{array}{c}\text { Final body } \\
\text { weight gain }(\mathrm{g})\end{array}$} & $\begin{array}{c}\text { Triglyceride } \\
(\mu \mathrm{g} / \mathrm{dl})\end{array}$ & $\begin{array}{c}\text { Cholesterol } \\
(\mu \mathrm{g} / \mathrm{dl})\end{array}$ \\
\hline Control & $1802.0 \pm 39.6^{\mathrm{b}}$ & $17.04 \pm 0.77^{\mathrm{b}}$ & $31.56 \pm 2.29^{\mathrm{b}}$ \\
\hline L. methionine & $1971.0 \pm 29.7^{\mathrm{a}}$ & $13.88 \pm 0.48^{\mathrm{c}}$ & $24.92 \pm 2.05^{\mathrm{c}}$ \\
\hline Choline & $1946.0 \pm 59.4^{\mathrm{a}}$ & $12.54 \pm 1.24^{\mathrm{c}}$ & $23.72 \pm 3.73^{\mathrm{c}}$ \\
\hline L. carnitine & $1932.6 \pm 24.6^{\mathrm{a}}$ & $12.82 \pm 0.94^{\mathrm{c}}$ & $25.34 \pm 2.31^{\mathrm{c}}$ \\
\hline Silymarin & $1924.0 \pm 22.2^{\mathrm{a}}$ & $16.32 \pm 0.78^{\mathrm{b}}$ & $28.08 \pm 3.45^{\mathrm{b}}$ \\
\hline 4 supplements & $1994.0 \pm 50.3^{\mathrm{a}}$ & $12.10 \pm 1.68^{\mathrm{c}}$ & $20.44 \pm 2.33$ \\
\hline Paracetamol & $1578.0 \pm 25.9^{\mathrm{c}}$ & $21.08 \pm 0.86^{\mathrm{a}}$ & $41.92 \pm 2.69^{\mathrm{a}}$ \\
\hline 4 supplements + paracetamol & $1741.0 \pm 46.7^{\mathrm{b}}$ & $16.66 \pm 0.79^{\mathrm{b}}$ & $31.02 \pm 2.18^{\mathrm{b}}$ \\
\hline
\end{tabular}

Data are presented as mean \pm SEM. Means carrying different superscript letters are significantly different at $\mathrm{p} \leq 0.05$

Table 2: Effect of the 4 supplements on liver damage enzymes and oxidant/antioxidant status

\begin{tabular}{|c|c|c|c|c|c|}
\hline & ALT (U/L) & $\overline{\text { AST (U/L) }}$ & $\overline{\text { GR (U/L) }}$ & $\overline{\mathrm{SOD}(\mathrm{U} / \mathrm{L})}$ & MDA (nm/ml) \\
\hline Control & $36.58 \pm 3.39^{b}$ & $132.81 \pm 3.37^{b}$ & $51.86 \pm 1.7^{b}$ & $65.30 \pm 1.63^{b}$ & $6.24 \pm 0.75^{b}$ \\
\hline L. methionine & $28.68 \pm 4.16^{c}$ & $118.28 \pm 5.54^{\mathrm{c}}$ & $61.54 \pm 2.8^{\mathrm{a}}$ & $69.90 \pm 1.88^{a}$ & $4.84 \pm 0.36^{\mathrm{c}}$ \\
\hline Choline & $28.16 \pm 3.72^{c}$ & $117.32 \pm 5.18^{\mathrm{c}}$ & $59.08 \pm 2.03^{\mathrm{a}}$ & $72.48 \pm 2.85^{\mathrm{a}}$ & $6.06 \pm 0.27^{b}$ \\
\hline L. carnitine & $27.14 \pm 4.74^{\mathrm{c}}$ & $113.26 \pm 5.04^{\mathrm{c}}$ & $58.26 \pm 2.89^{a}$ & $69.90 \pm 3.15^{\mathrm{a}}$ & $6.18 \pm 0.36^{b}$ \\
\hline Silymarin & $28.68 \pm 4.46^{c}$ & $118.82 \pm 3.80^{\mathrm{c}}$ & $59.12 \pm 3.21^{\mathrm{a}}$ & $70.32 \pm 2.09^{\mathrm{a}}$ & $6.08 \pm 0.30^{b}$ \\
\hline 4 supplements & $16.12 \pm 4.27^{\mathrm{d}}$ & $83.96 \pm 4.89^{\mathrm{d}}$ & $61.5 \pm 3.11^{\mathrm{a}}$ & $71.98 \pm 3.29^{\mathrm{a}}$ & $5.16 \pm 0.65^{\mathrm{c}}$ \\
\hline Paracetamol & $69.78 \pm 3.42^{\mathrm{a}}$ & $174.74 \pm 5.8^{\mathrm{a}}$ & $40.34 \pm 3.16^{c}$ & $47.56 \pm 6.80^{c}$ & $8.96 \pm 0.69^{a}$ \\
\hline $\begin{array}{l}4 \text { supplements } \\
+ \text { paracetamol }\end{array}$ & $40.46 \pm 4.43^{b}$ & $135.04 \pm 4.73^{b}$ & $49.0 \pm 1.8^{b}$ & $62.08 \pm 4.79^{b}$ & $6.72 \pm 0.48^{b}$ \\
\hline
\end{tabular}

Data are presented as mean \pm SEM. Means carrying different superscript letters are significantly different at $\mathrm{p} \leq 0.05$ 
Effect of the 4 supplements on glutathione reductase and superoxide dismutase

Chick fed diet supplemented with paracetamol exhibited a significant decrease in serum level of glutathione reductase (GR) and superoxide dismutase (SOD) as compared to the control group (Table 2). While L. methionine, choline, silymarin and combined groups showed a significant increase in these two enzymes, with best effect for combined group, as compared to the control group. Moreover, chicken administrated the 4 supplements and paracetamol showed a significant increase in GR and SOD as compared to the paracetamol group without statistical change relative to the control group. This indicates that these 4 supplements had the ability to increase the activity of antioxidant enzymes that was increased by paracetamol. Consistent with these results, Zhang, et al. (26) denoted that increasing methionine level above NRC recommendation for 500 male broiler chickens from one day old to 26 days of age led to increasing total glutathione and reduced glutathione in blood and breast muscle. Also, Jankowski, et al. (27) reported that increasing methionine level in broiler diets resulted in a significant increase in glutathione concentration and decreasing both malondialdehyde and plasma triglycerides levels. Furthermore, Ruan, et al. (28) reported that 120 one day old broilers supplemented with methionine deficient diet resulted in decreasing SOD, catalase and glutathione peroxidase. Similarly, Wang, et al. (29) reported that adding L. carnitine at a dose of 100 $\mathrm{mg} / \mathrm{kg}$ to broilers diet decreased MDA level in heart tissue, triglycerides content and increased SOD and GR.

\section{Effect of the 4 supplements on malondialde- hyde}

The paracetamol group showed a significant increase in malondialdehyde (MDA) level as compared to the control group. Only L. methionine and combined groups showed a significant decrease in MDA relative to the control group. Moreover, chicken administrated the 4 supplements and paracetamol showed a significant decrease in MDA as compared to the para- cetamol group without statistical change relative to the control group (Table 2). In agreement, Park, et al. (30) also reported that increasing methionine level during first 28 days of age of chicks resulted in decreasing plasma MDA and increasing total plasma glutathione level. In support, Mohammadi, et al. (31) also recorded that methionine supplementation in broilers at $1-42$ days of age at a concentration of $80 \mathrm{mg} / \mathrm{kg}$ of diet decreased plasma MDA level, reduced abdominal fat and plasma cholesterol level.

\section{Conclusion}

The present study reported that supplementation of poultry diets with L. methionine, L. carnitine, choline and silymarin improved chicken final body weight gain and enhance the negative impact of paracetamol through increasing the activity of glutathione reductase and superoxide dismutase and decreasing malondialdehyde, liver enzymes, cholesterol and triglycerides.

\section{Conflict of interest}

The authors declare that they have no conflict of interest.

\section{References}

1. Savita Marmat, Taj N Qureshi and Rathore H. Lethal doses of acetaminophen (paracetamol)for young broiler chicks. Indian Journal of pharmaceutical science and research 2015; 23-6.

2. Joulideh Pour Amin Reza. Effects of Acetaminophen as toxic drug on the liver function in poultry. Journal of cancer prevention and current research 2016; 4(4):100-28.

3. Gadde U, Kim W, Oh S and Lillehoj H. Alternatives to antibiotics for maximizing growth performance and feed efficiency in poultry. Animal Health Research Review 2017;18(1):26-45.

4. Mehri U, Herbert U and Mercier A. Addition of amino acids in poultry. Animal Health Research Review 2016; 12(1):23-35.

5. Saleh A A, Amber K, El-Magd M A, Atta M S, Mohammed A A, Ragab M M, Abd El-Kader H. Integrative effects of feeding Aspergillus awamori and fructooligosaccharide on growth performance and digestibility in broilers: promotion muscle protein metabolism, Biomed Res Int 2014; 2014: 946859.

6. Hayat Z, Rehman A, Akram K, Farooq U and Saleem G. Evaluation of a natural methionine 
source on broiler growth performance. Journal of Science and Food Agriculture 2015; 95 (12): 2462-6

7. Conde-Aguilera J, Cholet J, Lessire M, Mercier $\mathrm{Y}$, Tesseraud S, and van Milgenj. The level and source of free-methionine affect body composition and breast muscle traits in growing broilers. Poultry Science 2016; 95(10):2322-31.

8. Wen C, Jiang X, Ding L, Wang T and Zhou Y. Effects of dietary methionine on growth performance, meat quality and oxidative status of breast muscle in fast- and slow-growing broilers. Poultry Science 2017; 96(6):1707-14.

9. Albrecht A, Herbert U, Miskel D, Heinemann C, Braun C, Dohlen S, Zeitz J, Eder K, Saremi B and Kreyenschmidt J . Effect of methionine supplementation in chicken feed on the quality and shelf life of fresh poultrymeat. Poultry Science 2017; 96(8):2853-61.

10. Siegert W, Ahmadi H, Helmbrecht A and Rodehutscord M. A quantitative study of the interactive effects of glycine and serine with threonine and choline on growth performance in broilers. Poultry Science 2015; 94(7):1557-68.

11. Saunderson $C$ and Mackinlay J. Changes in body-weight, composition and hepatic enzyme activities in response to dietary methionine, betaine and choline levels in growing chicks. British Journal Nutrition 1990; 63(2):339-49.

12. Rehman Z, Chand N and Khan R. The effect of vitamin $\mathrm{E}$, L-carnitine, and ginger on production traits, immune response, and antioxidant status in two broiler strains exposed to chronic heat stress. Environment Science Poultry Research Institute 2017; 24(34):26851-7.

13. Leibetseder J. Effects of L-carnitine in poultry. Arch Tierernahr 1995; 48(1-2):97-108.

14. Xu Z, Wang M, Mao H, Zhan X and Hu C. Effects of L-carnitine on growth performance, carcass composition, and metabolism of lipids in male broilers. Poultry Science; 2003 82(3):408-13.

15. Yu Z, Wu F, Tian J, Guo X and An R. Protective effects of compound ammonium glycyrrhizin, L-arginine , silymarin and glucurolactone against liver damage induced by ochratoxin $\mathrm{A}$ in primary chicken hepatocytes. Mol Med Rep 2018; 18(3):2551-60.

16. Jahanian E, Mahdavi A, Asgary S and Jahanian $R$. Effects of dietary inclusion of silymarin on performance, intestinal morphology and ileal bacterial count in aflatoxin-challenged broiler chicks. Journal of Animal Physiology and Animal Nutrition 2017; 101(5):e43-54.
17. El-Magd M A, Khamis A, Nasr Eldeen S K, Ibrahim W M, Salama A F. Trehalose enhances the antitumor potential of methotrexate against mice bearing Ehrlich ascites carcinoma, Biomedicine \& Pharmacotherapy 2017; 92: 870-8.

18. Saleh A A, Amber K, El-Magd M A, Atta M S, Mohammed A A, Ragab M M, Abd El-Kader H. Integrative effects of feeding Aspergillus awamori and fructooligosaccharide on growth performance and digestibility in broilers: promotion muscle protein metabolism, Biomed Res Int 2014; 2014: 946859.

19. Alzahrani F A, El-Magd M A, AbdelfattahHassan A, Saleh A A, Saadeldin I M, El-Shetry E S, Badawy A A, Alkarim S. Potential Effect of Exosomes Derived from Cancer Stem Cells and MSCs on Progression of DEN-Induced HCC in Rats, Stem Cells International 2018; 2018: 17 https://doi.org/10.1155/2018/8058979.

20. Elkeiy M, Khamis A, El-Gamal M, Abo Gazia M, Zalat Z, El-Magd M. Chitosan nanoparticles from Artemia salina inhibit progression of hepatocellular carcinoma in vitro and in vivo, Environ Sci Pollut Res Int. doi: 10.1007/s11356-018-3339-6 2018.

21. Jahanian R and Khalifeh-Gholi M. Marginal deficiencies of dietary arginine and methionine could suppress growth performance and immunological responses in broiler chickens 2018; 102(1):e11-20.

22. Jahanian R and Ashnagar M. Effects of dietary supplementation of choline and carnitine on growth performance, meat oxidative stability and carcass composition of broiler chickens fed diets with different metabolisable energy levels. 2018; 59(4):470-6.

23. Khajali $\mathrm{F}$ and Khajali Z. L-Carnitine supplementation decreases lipid peroxidation and improves cardiopulmonary function in broiler chickens reared at high altitude .Acta Vet Hung 2014;62(4):489-99.

24. Tedesco D, Steidler S, Galletti S, Tameni M, Sonzogni O and Ravarotto L. Efficacy of silymarinphospholipid complex in reducing the toxicity of aflatoxin B1 in broilerchicks. Poultry Science 2004; 83 (11):1839-43.

25. Selvan R, Saravanakumar M, Suresh S, Chandrasekeran $\mathrm{C}$ and Prashanth D. Evaluation of polyherbal formulation and synthetic choline chloride on choline deficiency model in broilers: implications on zootechnical parameters, serum biochemistry and liver histopathology. Asian-Australas Journal of Animal Science 2018; 31(11):1795-806. 
26. Zhang S, Gilbert E, Saremi B and Wong E. Supplemental methionine sources have a neutral impact on oxidative status in broiler chickens. Journal of Animal Physiology and Animal Nutrition 2018; 102(5):1274-83.

27. Jankowski J, Ognik K, Kubinska M, Czech A, Juskiewicz J and Zdunczyk Z. The effect of DL, L-isomers and DL-hydroxy analog administered at 2 levels as dietary sources of methionine on the metabolic and antioxidant parameters and growth performance of broilers. Poultry Science 2017; 96(9):3229-38.

28. Ruan T, Li L, Lyu Y, Luo Q, Wu B. Effect of methionine deficiency on oxidative stress and apoptosis in the small intestine of broilers. Acta Vet Hung 2018; 66(1):52-65.
29. Wang Y, Ning D, Peng Y and Guo Y. Effects of Dietary L-carnitine Supplementation on Growth Performance, Organ Weight, Biochemical Parameters and Ascites Susceptibility in Broilers Reared Under Low-temperature Environment Asian-Australas Journal Animal Science 2013; 26(2):233-40.

30. Park I, Pasquetti T, Malheiros R, Ferket P and Kim S . Effects of supplemental L-methionine on growth performance and redox status of broilers compared with the use of DL-methionine. Poultry Science 2018; 97(1):102-9.

31. Mohammadi V, Ghazanfari S, MohammadiSangcheshmeh A and Nazaran M. Comparative effects of zinc-nano complexes, zinc-sulphate and zinc-methionine on performance in broiler chickens. British Poultry Science 2015; 56(4):486-93. 